\title{
Video Article \\ Activated Cross-linked Agarose for the Rapid Development of Affinity Chromatography Resins - Antibody Capture as a Case Study
}

\author{
Matthias Knödler ${ }^{1,3}$, Clemens Rühl ${ }^{2}$, Patrick Opdensteinen ${ }^{1,3}$, Johannes F. Buyel $1^{1,3}$ \\ ${ }^{1}$ Institute for Molecular Biotechnology, RWTH Aachen University \\ ${ }^{2}$ Sanofi Deutschland $\mathrm{GmbH}$ \\ ${ }^{3}$ Fraunhofer Institute for Molecular Biology and Applied Ecology IME, Fraunhofer-Gesellschaft zur Förderung der angewandten Forschung e. V.
}

Correspondence to: Johannes F. Buyel at johannes.buyel@rwth-aachen.de

URL: https://www.jove.com/video/59933

DOI: doi:10.3791/59933

Keywords: Biochemistry, Issue 150, Protein A replacements, chromatography resin, downstream processing (DSP), design of experiments (DoE), plant-made pharmaceuticals (PMPs), primary recovery

Date Published: 8/16/2019

Citation: Knödler, M., Rühl, C., Opdensteinen, P., Buyel, J.F. Activated Cross-linked Agarose for the Rapid Development of Affinity Chromatography Resins - Antibody Capture as a Case Study. J. Vis. Exp. (150), e59933, doi:10.3791/59933 (2019).

\section{Abstract}

The purification of monoclonal antibodies (mAbs) is commonly achieved by Protein A affinity chromatography, which can account for up to $25 \%$ of the overall process costs. Alternative, cost-effective capture steps are therefore valuable for industrial-scale manufacturing, where large quantities of a single $\mathrm{mAb}$ are produced. Here we present a method for the immobilization of a DsRed-based epitope ligand to a crosslinked agarose resin allowing the selective capture of the HIV-neutralizing antibody 2F5 from crude plant extracts without using Protein A. The linear epitope ELDKWA was first genetically fused to the fluorescent protein DsRed and the fusion protein was expressed in transgenic tobacco (Nicotiana tabacum) plants before purification by immobilized metal-ion affinity chromatography. Furthermore, a method based on activated cross-linked agarose was optimized for high ligand density, efficient coupling and low costs. The $\mathrm{pH}$ and buffer composition and the soluble ligand concentration were the most important parameters during the coupling procedure, which was improved using a design-of-experiments approach. The resulting affinity resin was tested for its ability to selectively bind the target $\mathrm{mAb}$ in a crude plant extract and the elution buffer was optimized for high mAb recovery, product activity and affinity resin stability. The method can easily be adapted to other antibodies with linear epitopes. The new resins allow gentler elution conditions than Protein A and could also reduce the costs of an initial capture step for mAb production.

\section{Video Link}

The video component of this article can be found at https://www.jove.com/video/59933/

\section{Introduction}

Biopharmaceutical products are important for the treatment of a broad spectrum of diseases in nearly every branch of medicine ${ }^{1}$. Monoclonal antibodies (mAbs) dominate the biopharmaceutical market, with worldwide sales expected to reach almost $€ 110$ billion in $2020^{2}$. The favored expression platform for mAbs are Chinese hamster ovary cell lines, which typically produce high mAb titers of up to $10 \mathrm{~g} \cdot \mathrm{L}^{-1}$ in the culture supernatant ${ }^{3,4}$. However, the production of mAbs in mammalian cell cultures is expensive due to the high cost of the medium and the need for sterile fermentation ${ }^{5}$. Alternative expression platforms such as plants potentially offer a faster, simpler, less expensive and more scalable approach for industrial manufacturing ${ }^{6,7}$.

In addition to the costs associated with mammalian cell cultures, the widespread use of Protein A affinity chromatography for product capture is a major cost driver for the industrial production of mAbs. Protein A is naturally found on the surface of Staphylococcus aureus cells and it binds to the fragment crystallizable $(\mathrm{Fc})$ region of certain murine and human antibodies, thereby acting as a defense mechanism to evade the humoral immune system ${ }^{8}$. Protein A has become the industry gold standard for the capture of mAbs from cell culture supernatants and is also widely used by the research community because it is highly selective, typically achieving mAb purities of $\sim 95 \%$ in a single step ${ }^{8}$. Unsurprisingly, sales of Protein A over the last two decades have closely mirrored the sales of mAbs ${ }^{8}$. Depending on the production scale, the costs of Protein A can correspond to more than $25 \%$ of the total process costs and thereby affect the market price of therapeutic mAbs, which can be up to $€ 2,000 \mathrm{~g}^{-15,9}$. Therefore, alternative chromatography resins with a similar purification performance have the potential to substantially reduce production costs, making antibody-based therapies accessible for a larger number of patients ${ }^{10,11,12}$. Such alternatives may also circumvent the disadvantages of Protein A chromatography, including the harsh elution conditions at low $\mathrm{pH}$ (typically $<3.5$ ) that can potentially cause mAbs to undergo conformational changes that promote aggregation ${ }^{13}$. Importantly, Protein A is selective only for the Fc region of certain IgG subclasses, so non-functional molecules with truncated binding domains may co-purify with the intact product ${ }^{5}$, whereas mAb derivaties such as single-chain variable fragments do not bind to Protein $A$ at all.

Here, we describe an alternative affinity chromatography resin for the capture of the HIV-neutralizing mAb 2F5 using its linear epitope ELDKWA (one letter amino acid code) ${ }^{5,14}$. We genetically fused the $2 \mathrm{~F} 5$ epitope to the C-terminus of the fluorescent protein DsRed, which functioned as a carrier and reporter molecule, and produced the resulting protein DsRed-2F5-Epitope (DFE) in transgenic tobacco (Nicotiana tabacum) plants. 
DFE was purified by single-step immobilized metal-ion affinity chromatography (IMAC). The immobilization of the purified DFE affinity ligand onto a cross-linked agarose resin was achieved by chemical coupling using $\mathrm{N}$-hydroxysuccinimide (NHS)-activated cross-linked agarose columns. Statistical experimental designs were then used to optimize the immobilization procedure and coupling efficiency ${ }^{15}$. The purification strategy for mAb 2F5 was evaluated in terms of antibody purity, yield and ligand stability. In contrast to Protein A, which binds the Fc region, DFE bound to the complementarity-determining region of $2 \mathrm{~F} 5$, ensuring the purification of molecules with an intact paratope. Our concept can easily be adapted to any $\mathrm{mAb}$ with a linear epitope or to other peptide-based affinity ligands which can be easily identified by microarray studies ${ }^{16}$.

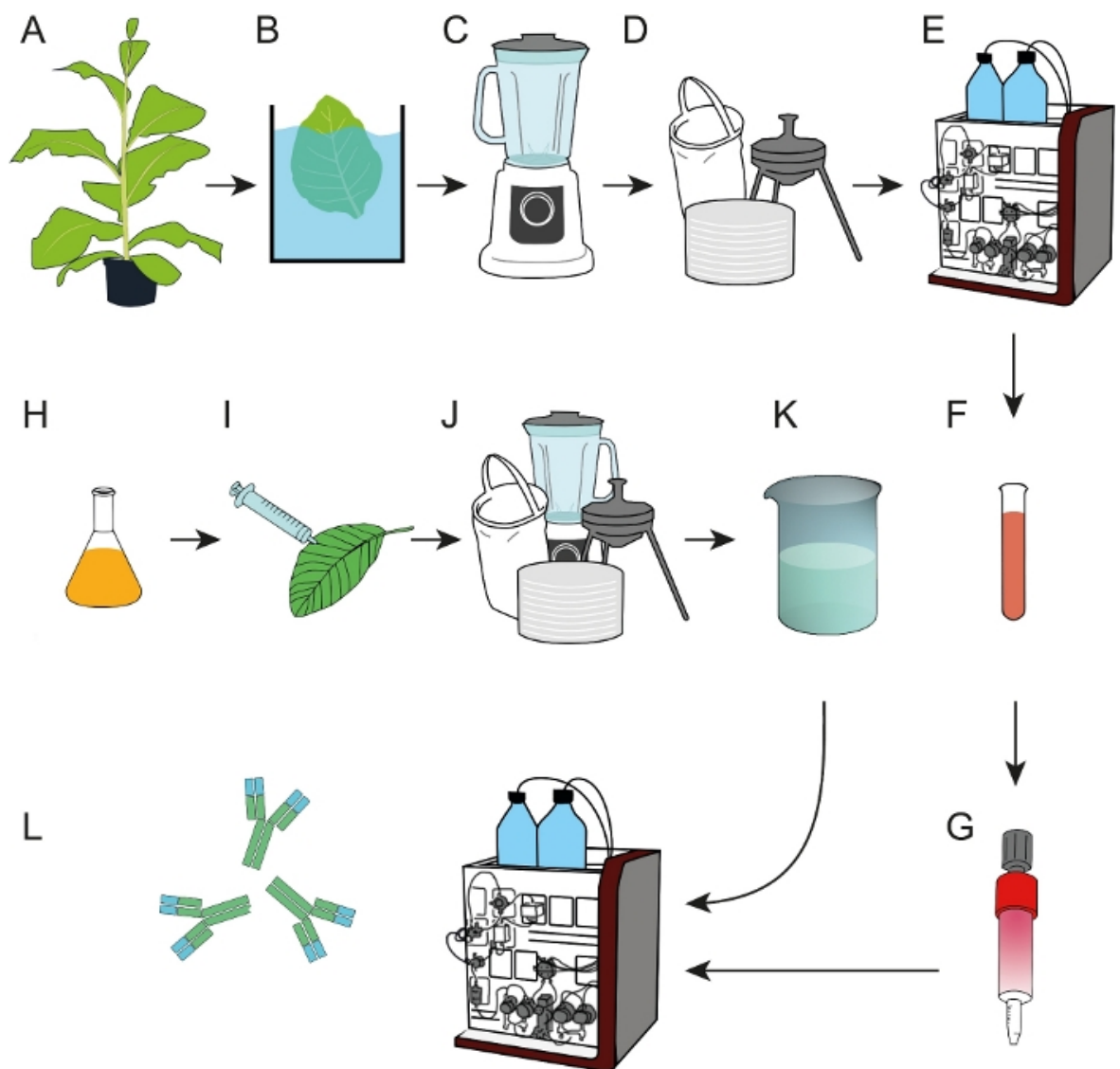

Figure 1: Process flow scheme for the preparation of epitope affinity resins that can be used for the capture of mAbs from crude plant extracts or cell culture supernatants. (A) The affinity ligand DFE was expressed in transgenic tobacco plants. A heat precipitation step (B) was included before harvested leaves were homogenized (C). (D) The crude plant extract was clarified by bag filtration, depth filtration and 0.2 $\mu \mathrm{m}$ sterile filtration. (E) DFE was then purified by IMAC. (F, G) The purified DFE affinity ligand was immobilized on EDC/NHS-activated crosslinked agarose columns. (H) Bacterial cultures carrying T-DNA encoding antibody $2 \mathrm{~F} 5$ were used for transient expression in $N$. benthamiana plants (I) grown in a phytotron. (J) N. benthamiana leaves were harvested and processed as described in D. (K) mAb $2 F 5$ was purified from the clarified extract using the DFE affinity columns (L). Please click here to view a larger version of this figure.

\section{Protocol}

\section{Cultivate the Transgenic Tobacco Plants}

NOTE: The design of the DFE fusion protein and the generation of transgenic plants are described elsewhere ${ }^{5,17}$.

1. Germinate the transgenic tobacco seedlings in soil. Irrigate the plants with a $1.0 \mathrm{~g} \cdot \mathrm{L}^{-1}$ fertilizer solution. Transfer the plants to single, $100 \mathrm{~mm}$ $\times 100 \mathrm{~mm} \times 60 \mathrm{~mm}$ (length, width, height) pots when they grow to a diameter of $\sim 0.04 \mathrm{~m}$.

2. Cultivate the transgenic tobacco plants in a greenhouse with a 16 -h photoperiod $\left(25 / 22{ }^{\circ} \mathrm{C}\right.$ light/dark temperature regime), with $70 \%$ relative humidity and automated fertilization with a $1.0 \mathrm{~g} \cdot \mathrm{L}^{-1}$ fertilizer solution for $15 \mathrm{~min}$ every hour.

3. After 7 weeks, harvest all leaves except the four cotyledon leaves at the base of the plant stem. Immediately process the harvested leaves as described below.

\section{Heat Precipitation of Host Cell Proteins}

1. Set up a water bath with a $20 \mathrm{~L}$ working volume in a stainless-steel heated vessel $(0.3 \mathrm{~m} \times 0.3 \mathrm{~m} \times 0.3 \mathrm{~m})$. At the start, place a magnetic pump in the water bath to agitate the liquid permanently with a flow of $5 \mathrm{~L} \mathrm{~min}{ }^{-1}$. Mount an adjustable thermostat on the water bath for temperature control (steps 2.4 and 2.8 ). 
CAUTION: All the following steps up to 2.10 involve the handling of hot liquid. Wear appropriate personal protective equipment including thermally insulated gloves and goggles.

2. Add $15 \mathrm{~L}$ of deionized water to the water bath and heat the liquid to $70^{\circ} \mathrm{C}$.

3. Place a $10 \mathrm{~L}$ bucket filled with $5 \mathrm{~L}$ of deionized water on a magnetic stirrer. Add sodium phosphate to a final concentration of $120 \mathrm{mM}$. Adjust the $\mathrm{pH}$ to 8.14 using $10 \mathrm{M}$ hydrochloric acid. When all the components have dissolved, add the resulting concentrated blanching buffer $(5 \mathrm{~L})$ to the water bath from step 2.2 .

4. Agitate the water bath until the temperature reaches $70^{\circ} \mathrm{C}$. Use $10 \mathrm{M}$ hydrochloric acid to adjust the $\mathrm{pH}$ to 8.14 if necessary. Continue agitating for at least $15 \mathrm{~min}$ after the required temperature and $\mathrm{pH}$ are reached to ensure that the entire assembly is in thermal equilibrium.

5. Prepare a $20 \mathrm{~L}$ bucket $(0.3 \mathrm{~m} \times 0.3 \mathrm{~m} \times 0.3 \mathrm{~m})$ filled with deionized water at a temperature of $\sim 17^{\circ} \mathrm{C}$ (required for step 2.9 ).

6. Prepare $400 \mathrm{~g}$ aliquots of the harvested tobacco leaves from step 1.3. Place one aliquot in a perforated basket $(0.2 \mathrm{~m} \times 0.2 \mathrm{~m} \times 0.2 \mathrm{~m}$; pore width at least $0.02 \mathrm{~m} \times 0.02 \mathrm{~m}$ ). Avoid overfilling the basket with plant material or packing the leaves too tightly to avoid damaging the tissue.

7. Fully submerge the basket in the hot blanching buffer from step 2.4 and make sure all leaves remain under the liquid surface. Use a thermostable silicone spoon to hold the leaves under the surface if necessary.

8. Incubate the tobacco leaves for $1.5 \mathrm{~min}$ in the blanching fluid while the pump is still agitating the liquid. Monitor the liquid temperature during the entire incubation period. Avoid blocking the pump inlet with tobacco leaves.

9. Remove the basket of tobacco leaves from the blanching buffer and drain residual buffer from the leaves for $30 \mathrm{~s}$. Transfer the basket to the bucket filled with cold water (from step 2.5) and immerse the leaves for $30 \mathrm{~s}$. Remove the basket and drain residual water from the leaves for $30 \mathrm{~s}$ before homogenization (step 3 ).

10. Repeat steps 2.6 to 2.9 with fresh aliquots from 2.6 until the entire harvested biomass is processed. Constantly monitor and adjust the pH and the temperature of the blanching buffer in the water bath.

NOTE: Blanched plant material can be stored on ice for up to $30 \mathrm{~min}$ when several blanching cycles are required to process the entire biomass. Blanched leaves can also be stored in vacuum-sealed bags at $-80^{\circ} \mathrm{C}$ for at least 3 weeks. However, immediate processing is recommended because prolonged storage can reduce the DFE yield.

\section{Protein Extraction and Clarification}

CAUTION: The following steps involve a blender with rotating blades. Do not work in the blender vessel when powered or mounted on the motor unit.

1. Place $150 \mathrm{~g}$ (wet mass) of blanched tobacco leaves (step 2.9) in the blender vessel and add $450 \mathrm{~mL}$ of extraction buffer (50 mM sodium phosphate, $500 \mathrm{mM}$ sodium chloride, $10 \mathrm{mM}$ sodium disulfite, $\mathrm{pH}$ 7.5). Close the blender cap tightly to prevent the spilling of plant material or buffer.

2. Homogenize the leaves for $3 x$ for $30 \mathrm{~s}$, with $30 \mathrm{~s}$ breaks between each pulse. Ensure that all leaves are homogenized and that none stick to the top of the blender vessel. If necessary, open the blender during the breaks and push down leaves that stick at the upper part of the vessel, using a clean silicone spoon.

3. After homogenization, take a $1.0 \mathrm{~mL}$ sample of the homogenate for subsequent analysis (step 7).

4. Collect the homogenate in a vessel of adequate size (e.g. if working with a total biomass of $1.0 \mathrm{~kg}$, use a vessel with a capacity of at least a 5 L). Repeat steps 3.1 to 3.3 until all of the blanched biomass is homogenized.

5. Mount a bag filter into a filter mount and place another adequately sized vessel (see 3.4) beneath the assembly. Apply the homogenate to the bag filter at a rate of $\sim 0.15 \mathrm{~L} \mathrm{~min}^{-1}$. Take samples of the bag filtrate after each liter for subsequent analysis (step 7) and measure the turbidity of the bag filtrate pool as a 1:10 dilution in extraction buffer using a turbidimeter or similar device.

6. Further clarify the bag filtrate pool using $0.02 \mathrm{~m}^{2}$ of a K700 (top) and KS50 (bottom) depth filter layer combination per liter of bag filtrate pool. Apply a flow rate of $3.0 \mathrm{~L} \mathrm{~min}^{-1} \cdot \mathrm{m}^{-2}$ up to a maximum pressure of $0.2 \mathrm{MPa}$. Then remove residual particles by passing the clarified filtrate through a $0.2 \mu \mathrm{m}$ sterile filter as previously described ${ }^{5}$.

\section{Purification of the DFE Affinity Ligand}

1. Prepare a fast protein liquid chromatography system by flushing with elution buffer (10 $\mathrm{mM}$ sodium phosphate, $300 \mathrm{mM}$ imidazole, $\mathrm{pH} 7.4$ ), wash buffer (10 mM sodium phosphate, $\mathrm{pH} 7.4$ ) and equilibration buffer (20 mM sodium phosphate, $500 \mathrm{mM}$ sodium chloride, $\mathrm{pH} 7.4)$. Mount a column containing $\sim 50 \mathrm{~mL}$ of chelating cross-linked agarose resin per kilogram of leaf biomass $(\sim 2.5 \mathrm{~L}$ depth filtrate).

2. Charge the column with nickel ions by applying 5 column volumes (CV) of $200 \mathrm{mM}$ nickel sulfate solution and wash it with $5 \mathrm{CV}$ of elution buffer. Use a flow rate of $50 \mathrm{~cm} \mathrm{~h}^{-1}$ and monitor the UV signals at 260, 280 and $558 \mathrm{~nm}$ for all subsequent chromatography steps.

3. Equilibrate the column with $10 \mathrm{CV}$ of equilibration buffer. Then load $50 \mathrm{CV}$ of the clarified plant extract (from step 3.6) onto the conditioned column.

4. Wash the column with $10 \mathrm{CV}$ of wash buffer. Elute the DFE fusion protein with $5 \mathrm{CV}$ elution buffer and collect the product-containing fraction once the UV signals at $280 \mathrm{~nm}$ and $558 \mathrm{~nm}$ have increased to more than $5 \mathrm{mAU}$ above the baseline.

5. Take a $0.2 \mathrm{~mL}$ sample from the elution fraction in order to measure the total soluble protein (TSP) concentration (step 7.1), DFE concentration (steps 7.2 and 7.3), and DFE purity (step 7.4).

6. Mount a column containing $\sim 50 \mathrm{~mL}$ of cross-linked dextran resin on a chromatography system. Equilibrate the column with $5 \mathrm{CV}$ of coupling buffer (200 mM HEPES, $500 \mathrm{mM}$ sodium chloride, pH 8.5). Inject $10 \mathrm{~mL}$ of the DFE elution fraction (step 4.4) for buffer exchange and monitor the UV absorbance at 280 and $558 \mathrm{~nm}$.

7. Collect the DFE-containing fraction once the UV signals at $280 \mathrm{~nm}$ and $558 \mathrm{~nm}$ have increased to more than $5 \mathrm{mAU}$ above the baseline. Take a $0.2 \mathrm{~mL}$ sample and determine the TSP concentration, DFE concentration, and DFE purity (step 7).

8. Concentrate the purified DFE sample (from step 4.7) to $15 \mathrm{~g} \mathrm{~L}^{-1}$ using a centrifugal concentrator tube at $3,000 \times \mathrm{g}$ at $4{ }^{\circ} \mathrm{C}$ for $30 \mathrm{~min}$ in a centrifuge. Continue with the coupling reaction (step 5).

NOTE: Store the DFE solution at $4{ }^{\circ} \mathrm{C}$ if the concentration or coupling steps cannot be carried out immediately. 


\section{Coupling DFE to the Activated Cross-linked Agarose Resin}

NOTE: Do not replace the isopropanol used for the storage of NHS-activated columns until all equipment and solutions for coupling are ready. Never let the columns run dry.

1. Setup a design of experiments (DoE) model to optimize the coupling of DFE to the activated resin, with $\mathrm{pH}$, buffer composition and DFE concentration as factors. The details of the DoE method are described elsewhere ${ }^{15}$.

2. Prepare the affinity ligand solution (from step 4.8) in a concentration range from $0.5-15 \mathrm{~g} \cdot \mathrm{L}^{-1}$ or as defined in the DoE and store it on ice until the coupling reaction is ready (step 5.5). Fill at least ten $2 \mathrm{~mL}$ syringes with the DFE solution and prepare an adapter to mount the syringes on NHS-activated cross-linked agarose columns with a bed volume of $1.0 \mathrm{~mL}$.

3. For every 10 columns used for coupling, prepare $30 \mathrm{~mL}$ of deactivation solution ( $0.5 \mathrm{M}$ ethanolamine, $0.5 \mathrm{M}$ sodium chloride, $\mathrm{pH} 8.3$ ), $30 \mathrm{~mL}$ of low-pH solution ( $0.1 \mathrm{M}$ sodium acetate, $0.5 \mathrm{M}$ sodium chloride, $\mathrm{pH} 4.0)$ and $10 \mathrm{~mL}$ of storage solution $(0.05 \mathrm{M}$ disodium phosphate, $0.1 \%$ $(\mathrm{m} / \mathrm{v})$ sodium azide, $\mathrm{pH} 7.0)$.

4. Prepare $20 \mathrm{~mL}$ of $1 \mathrm{mM}$ hydrochloric acid in a tube and incubate it on ice for at least $20 \mathrm{~min}$. Prepare a precision scale to monitor the flowthrough fractions for all steps during the coupling reaction (step 5.7).

5. Open a sealed NHS-activated cross-linked agarose column and mount the syringe adapter at the column inlet. Prevent any air entering the column by applying a drop of buffer onto the adapter inlet before connecting it to the syringe.

6. Wash the column with $6 \mathrm{~mL}$ of ice-cold $1 \mathrm{mM}$ hydrochloric acid (from step 5.4) at a flow rate of $<1 \mathrm{~mL} \mathrm{~min}^{-1}$ and immediately proceed to step 5.7 .

7. Inject $1.5 \mathrm{~mL}$ of DFE solution (step 5.2) using a $2 \mathrm{~mL}$ syringe at a flow rate of $<1 \mathrm{~mL} \mathrm{~min}{ }^{-1}$ and collect the flow-through fraction on a precision scale (step 5.4) for subsequent analysis (step 7). Seal the column at both ends and incubate for $15-45$ min at $22^{\circ} \mathrm{C}$, depending on the DoE setup.

8. Inject $6 \mathrm{~mL}$ of deactivation solution followed by $6 \mathrm{~mL}$ of low-pH solution at a flow rate of $<1 \mathrm{~mL} \mathrm{~min}^{-1}$ to remove non-covalently bound ligands from the resin. Then inject $6 \mathrm{~mL}$ of deactivation solution and incubate the column for $15 \mathrm{~min}$.

9. Inject $6 \mathrm{~mL}$ of low-pH solution into the column, followed by $6 \mathrm{~mL}$ of deactivation solution. Then inject another $6 \mathrm{~mL}$ of low-pH solution into the column.

10. Inject $2 \mathrm{~mL}$ of storage solution into the column and store at $4{ }^{\circ} \mathrm{C}$

\section{Testing the Purification of mAbs from Clarified Plants Extracts}

1. Prepare $100 \mathrm{~mL}$ of clarified plant extract containing $2 \mathrm{~F} 5^{5}$ or the supernatant from the preferred cell-based expression system, also containing 2F5.

2. Prepare equilibration buffer ( $20 \mathrm{mM}$ sodium phosphate, $500 \mathrm{mM}$ sodium chloride, $\mathrm{pH} 7.4)$, low-pH elution buffer $(0.05 \mathrm{M}$ citrate, $0.05 \mathrm{M}$ sodium chloride, $\mathrm{pH}$ 4.0-3.25), and high-ionic-strength elution buffer (1.0-4.0 M magnesium chloride, 0.1 M HEPES, pH 8.0)

3. Flush the chromatography system with the buffers. Mount a DFE affinity column (from step 5.10) on the chromatography system and equilibrate with $5 \mathrm{CV}$ of equilibration buffer at a flow rate of $1.0 \mathrm{~mL} \mathrm{~min}^{-1}$. Monitor the UV absorbance at $280 \mathrm{~nm}$.

NOTE: Loading plant extract or cell culture supernatant onto the column can cause an increase in backpressure. Set a high-pressure alert at $0.2 \mathrm{MPa}$ to avoid damage to the chromatography system or DFE column.

4. Load $80 \mathrm{~mL}$ of the clarified plant extract or supernatant (step 6.1) onto the column at a flow rate of $0.5 \mathrm{~mL} \mathrm{~min}^{-1}$ to guarantee a contact time of $2 \mathrm{~min}$. Collect the flow-through samples in $2 \mathrm{~mL}$ fractions for breakthrough curve reconstruction (step 7.3). Store the flow-through samples at $4{ }^{\circ} \mathrm{C}$ if immediate sample analysis is not possible.

5. Wash the column with $6 \mathrm{CV}$ of equilibration buffer. Collect a sample of the wash at the beginning, middle and end of this step.

6. Elute mAb $2 \mathrm{~F} 5$ with $5 \mathrm{CV}$ of low-pH elution buffer or high-ionic-strength elution buffer (0.1 M HEPES, $1.25 \mathrm{M}$ magnesium chloride, $\mathrm{pH}$ 8.0). Collect the DFE fraction when the UV $280 \mathrm{~nm}$ signal has increased to $5 \mathrm{mAU}$ above the baseline.

1. Optimize the elution buffer for each epitope-antibody pair. For $2 \mathrm{~F} 5,1.25 \mathrm{M}$ magnesium chloride achieved an optimal balance between product recovery and ligand stability.

NOTE: The magnesium chloride solution is prone to precipitation. Therefore, dissolve the magnesium chloride in $\sim 700 \mathrm{~mL}$ of water. Separately dissolve the HEPES in $100 \mathrm{~mL}$ of water and adjust the $\mathrm{pH}$ to 8.0. Add the dissolved magnesium chloride solution to the HEPES solution and add water to a final volume of $1.0 \mathrm{~L}$. Do not adjust the $\mathrm{pH}$ after dissolving the magnesium chloride because this will cause precipitation.

7. Analyze all samples taken during steps 6.4-6.6 using the Bradford method, lithium dodecylsulfate polyacrylamide gel electrophoresis (LDSPAGE) and surface plasmon resonance (SPR) spectroscopy (step 7).

\section{Sample Analysis}

1. Measure the TSP concentration using the Bradford method ${ }^{18,19}$

1. In triplicate, pipette $2.5 \mu \mathrm{L}$ of each sample into a single well of a 96 -well plate. Use eight bovine serum albumin (BSA) standards in triplicate covering the range $0-2,000 \mathrm{mg} \cdot \mathrm{L}^{-1}$.

2. Add $200 \mu \mathrm{L}$ of Bradford reagent to each well and mix by gently pipetting up and down. Keep the pipette level to avoid the formation of bubbles that distort the subsequent readout.

3. Incubate the plate for $10 \mathrm{~min}$ at $22^{\circ} \mathrm{C}$ and measure the absorbance at $595 \mathrm{~nm}$ in a spectrophotometer. Calculate the TSP concentration in the samples based on a standard curve through the BSA reference points.

\section{Quantify DFE by fluorimetry}

1. In triplicate, pipette $50 \mu \mathrm{L}$ of each sample into single wells of a black 96 -well half-area plate. Include six DsRed standards covering the range $0-225 \mathrm{mg} \cdot \mathrm{L}^{-1}$. 
2. Measure the fluorescence twice using a $530 \pm 30 \mathrm{~nm}$ excitation filter and a $590 \pm 35 \mathrm{~nm}$ emission filter in a spectrophotometer. Calculate the DFE concentration in the samples based on a standard curve through the DsRed reference points.

3. Measure the 2F5 concentration by SPR spectroscopy ${ }^{20}$.

1. Prepare the HBS-EP running buffer (10 mM 4-(2-hydroxyethyl)-1-piperazineethanesulfonic acid (HEPES), $3 \mathrm{mM}$ ethylenediaminetetraacetic acid (EDTA), $150 \mathrm{mM}$ sodium chloride, $0.005 \% \mathrm{v} / \mathrm{v}$ Tween-20, $\mathrm{pH} 7.4$ ) and filter sterilize it by passing it through a $0.2 \mu \mathrm{m}$ vacuum bottle-top filter. Degas the buffer for $15 \mathrm{~min}$.

2. Connect the HBS-EP running buffer to the SPR instrument before docking a carboxymethylated dextran surface chip and equilibrate the system using the prime function. Start a manual run with a flow rate of $30 \mu \mathrm{L} \mathrm{min}{ }^{-1}$ and condition the chip surface by alternately injecting $30 \mathrm{mM}$ hydrochloric acid and $25 \mathrm{mM}$ sodium hydroxide (two injections each) over flow cells 1 and 2 at a flow rate of $30 \mu \mathrm{L}$ $\min ^{-1}$ for 1 min.

3. Prepare $300 \mu \mathrm{L}$ of a $500 \mathrm{mg} \cdot \mathrm{L}^{-1}$ Protein A solution in $10 \mathrm{mM}$ sodium acetate $(\mathrm{pH} 4.0)$. Thaw vials containing $0.4 \mathrm{M}$ 1-ethyl-3-(3dimethylaminopropyl) carbodiimide hydrochloride (EDC) and $0.1 \mathrm{M} \mathrm{NHS}$ and centrifuge at $16,000 \times \mathrm{g}$ for 1 min before mixing $70 \mu \mathrm{L}$ of EDC and $70 \mu \mathrm{L}$ of NHS.

4. Transfer the EDC/NHS mixture and the Protein A solution to $7 \mathrm{~mm}$ plastic sample vials and place in the sample rack. Activate the carboxymethylated dextran chip surface by injecting the EDC/NHS mixture over flow cells 1 and 2 at a flow rate of $10 \mu \mathrm{L}$ min $^{-1}$ for 10 $\min$.

5. Couple Protein A to the activated carboxymethylated dextran surface by injecting the Protein A solution over flow cell 2 at a flow rate of $15 \mu \mathrm{L} \min ^{-1}$ for $15 \mathrm{~min}$.

6. While coupling the Protein $\mathrm{A}$, thaw a vial of $1.0 \mathrm{M}$ ethanolamine hydrochloride $(\mathrm{pH} 8.5)$ and centrifuge at $16,000 \times g$ for 1 min. Transfer $150 \mu \mathrm{L}$ to a $7-\mathrm{mm}$ plastic vial and place into the instrument. When step 7.3 .5 is complete, deactivate the chip surface by injecting the ethanolamine solution over flow cells 1 and 2 at a flow rate of $10 \mu \mathrm{L} \mathrm{min}{ }^{-1}$ for $7 \mathrm{~min}$.

7. Condition the chip surface by alternately injecting $30 \mathrm{mM}$ hydrochloric acid and $25 \mathrm{mM}$ sodium hydroxide (two injections each) over

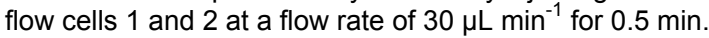

8. Prepare standards of antibody $2 \mathrm{~F} 5$ in HBS-EP running buffer at a concentration of $500 \mu \mathrm{g} \cdot \mathrm{L}^{-1}$ and dilute samples containing $2 \mathrm{~F} 5$ in HBS-EP to a final concentration in the range $20-1,000 \mu \mathrm{g} \cdot \mathrm{L}^{-1}$. Inject samples and standards over flow cells 1 and 2 at a flow rate of 30 $\mu \mathrm{L} \min ^{-1}$ for $3 \mathrm{~min}$. Inject a $2 \mathrm{~F} 5$ standard after every 15 samples.

9. Subtract the relative units (RU) signal of flow cell 1 (reference cell) from the signal of flow cell 2 (measurement cell) for each sample and calculate the antibody concentration based on the RU signal of $2 \mathrm{~F} 5$ standard injections.

10. After every sample or standard injection, regenerate the chip surface by injecting $30 \mathrm{mM}$ hydrochloric acid at a flow rate of $30 \mu \mathrm{L}$ min ${ }^{-1}$ for 0.5 min over flow cells 1 and 2.

11. Plot the $2 \mathrm{~F} 5$ concentration for each flow-through sample from step 6.4 against the flow through volume to obtain the $2 \mathrm{~F} 5$ breakthrough curve. Calculate the amount of injected $2 \mathrm{~F} 5$ when $10 \%$ of the loading $2 \mathrm{~F} 5$ concentration was reached to obtain the $10 \%$ dynamic binding capacity (DBC).

\section{Analyze protein samples by LDS-PAGE.}

1. Open a ready-to-use $4-12 \%$ BisTris LDS polyacrylamide gel and place it in an electrophoresis module. Transfer $800 \mathrm{~mL}$ of running buffer $(50 \mathrm{mM}$ MES, $50 \mathrm{mM}$ Tris base, $0.1 \%(\mathrm{~m} / \mathrm{v})$ SDS, $1 \mathrm{mM}$ EDTA, $\mathrm{pH} 7.3)$ into the module and add $0.5 \mathrm{~mL}$ of antioxidant solution.

2. In a $1.5 \mathrm{~mL}$ reaction tube, mix $10 \mu \mathrm{L}$ of loading buffer with $4 \mu \mathrm{L}$ of reducing agent and $26 \mu \mathrm{L}$ of the protein sample. Incubate the tube in a heat block for $10 \mathrm{~min}$ at $80^{\circ} \mathrm{C}$. Centrifuge the tube at $500 \times \mathrm{g}$ for $30 \mathrm{~s}$.

3. Load the LDS polyacrylamide gel ( $10 \mu \mathrm{L}$ of sample per lane) and load $5 \mu \mathrm{L}$ of pre-stained protein standard (10-180 kDa) in a separate lane.

4. Close the electrophoresis chamber and connect the power supply. The electrophoresis should run for 40 min and at constant $200 \mathrm{~V}$.

5. Remove the gel from the electrophoresis chamber. Open the gel sheathing and wash the gel for $15 \mathrm{~min}$ in water on a shaker at $19 \mathrm{rpm}$. Stain the gel for $1 \mathrm{~h}$ in staining solution on a shaker at $19 \mathrm{rpm}$.

6. Destain the gel for $1 \mathrm{~h}$ in water on a shaker at $19 \mathrm{rpm}$. Scan the gel using a film scanner.

\section{Representative Results}

\section{Expression and purification of the affinity ligand}

The fusion protein DFE was expressed in transgenic tobacco plants grown in a greenhouse. The yield was $\sim 120 \mathrm{mg} \cdot \mathrm{kg}^{-1}$ leaf mass with an average biomass of $\sim 130 \mathrm{~g}$ per plant. The DFE purity was $<5 \%$ of TSP in crude plant extracts before blanching but increased to $\sim 40 \%$ after heat treatment at $70{ }^{\circ} \mathrm{C}$ for $1.5 \mathrm{~min}$, which precipitated $>97 \%$ of the host cell proteins. The blanching step was easily integrated into the harvesting and extraction routine (Figure 1) and took less than $2 \mathrm{~h}$ of extra time, including setting up the water bath. The overall recovery of DFE was 23.5 $\mathrm{mg} \mathrm{kg}^{1}$ with a purity of $>90 \%$. The steps responsible for product loss were blanching, depth filtration and IMAC, with specific losses of $40 \%, 27 \%$ and $45 \%$, respectively. The depth filter capacity was on average $135 \pm 36 \mathrm{~L} \mathrm{~m}^{-2}( \pm S D, n=3)$ and thus in the upper range of values reported in the literature ${ }^{21}$. The DFE yield increased with plant age (Figure 2).

\section{Immobilization of the affinity ligand on NHS-activated chromatography columns}

During initial coupling tests, we found that HEPES buffer ( $\mathrm{pH} 8.3$ ) increased the coupling efficiency to $89 \pm 6 \%( \pm S D, n=3)$ compared to $78 \pm 9 \%$ $( \pm S D, n=3)$ for the bicarbonate buffer recommended by the manufacturer. Therefore, HEPES was used for all subsequent coupling experiments. A DoE approach was selected to optimize the coupling efficiency of DFE to NHS-activated cross-linked agarose resin. The absolute amount of DFE immobilized on the resin increased with the mass of DFE injected into the column and plateaued at $\sim 15 \mathrm{~g} \cdot \mathrm{L}^{-1}$ whereas the coupling yield declined continuously as more DFE was injected (Figure 2). The coupling yield was also $>50 \%$ lower in an acidic buffer, indicating the need to screen for suitable coupling conditions for each ligand on a case-by-case basis. Ideal conditions in terms of coupling yield, absolute quantity of immobilized DFE and column costs were identified using the numerical optimization tool of the DoE software. The most desirable conditions ( $\mathrm{pH} 9.0$ and $7.0 \mathrm{mg}$ of DFE per $1 \mathrm{~mL}$ of cross-linked agarose resin) were located on a large plateau and were therefore robust. The 
DFE molecules retained their red fluorescence even after coupling, and the color intensity corresponded to the total amount of immobilized DFE (Figure 2). Therefore, column color can be used as a simple quality control parameter to estimate the coupling efficiency and column quality. The fluorescence also confirmed that DFE fusion protein assembled in the tetrameric state of native DsRed.

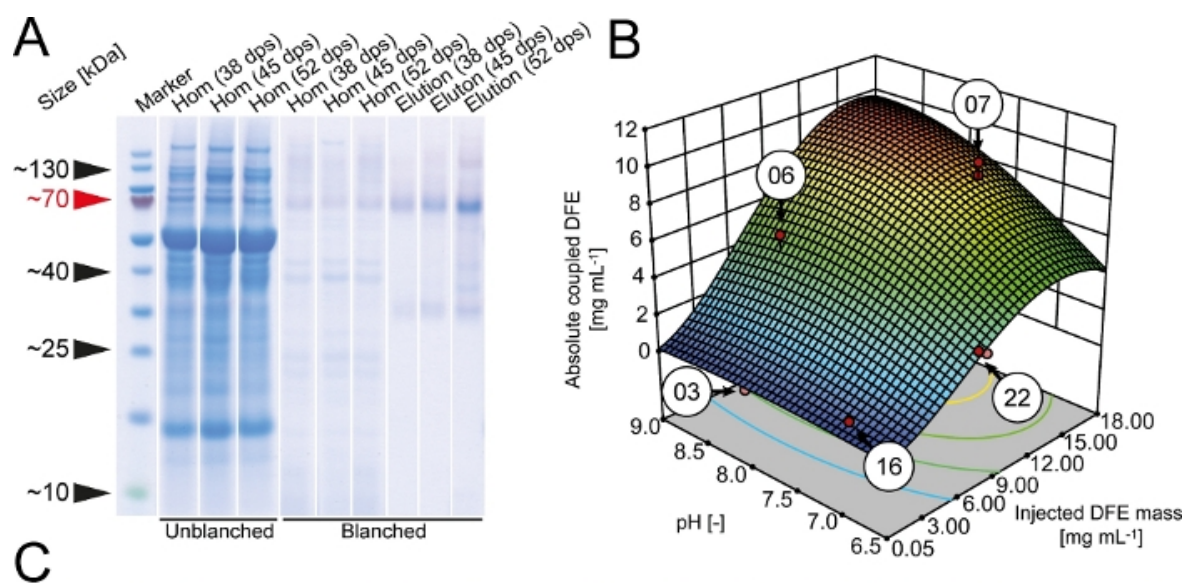

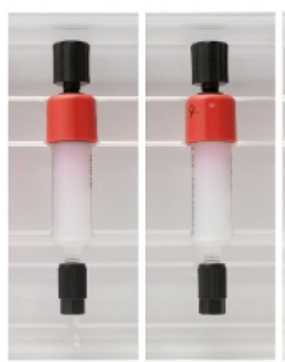

03

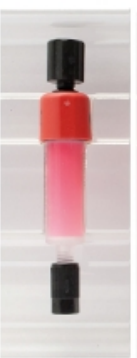

06

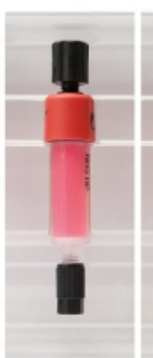

07

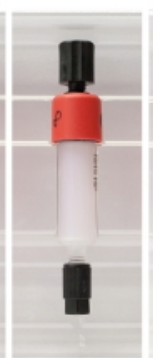

08

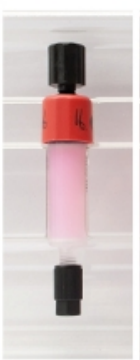

16

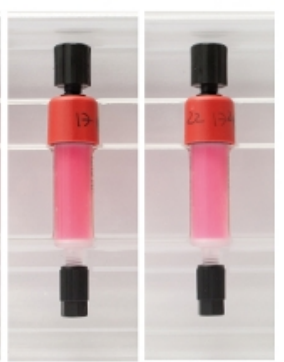

22

Figure 2: Optimization of DFE immobilization to NHS-activated cross-linked agarose resin. (A) LDS-PAA gel with western blot overlay of homogenate and elution samples from unblanched and blanched transgenic DFE plant extracts. Harvest of plants was performed 38,45 or 52 days after seeding. Western blots were performed using an anti-His ${ }_{6}$-antibodies ${ }^{5}$. (B) Total amount of coupled DFE affinity ligand in dependence if coupling $\mathrm{pH}$ and overall mass of purified DFE injected onto NHS-activated cross-linked agarose columns. Red dots indicate the actual experiments performed to build the response surface model. (C) DFE affinity columns after the coupling procedure. The numbers correspond to the coupling conditions highlighted in panel B. dps = days post seeding. Please click here to view a larger version of this figure.

\section{Testing 2F5 isolation using the DFE affinity resin}

The recombinant $2 \mathrm{~F} 5$ antibody was transiently produced in Nicotiana benthamiana plants grown in a phytotron ${ }^{5}$. The capture of $2 \mathrm{~F} 5$ from the crude plant extract was tested using affinity columns coupled with $\sim 7.0 \mathrm{mg}$ purified DFE (step 6 ). Elution from Protein A resins usually involves an acidic buffer $(\mathrm{pH} \sim 3.3)^{13}$. Therefore, we initially evaluated different low-pH elution buffers $(\mathrm{pH} 6.0-3.25)$ for the DFE columns. The elution of $2 \mathrm{~F} 5$ was successful at $\mathrm{pH}$ values below 4.5 with the highest recovery of $\sim 35 \%$ at $\mathrm{pH} 3.25$. However, low-pH elution inactivated both the antibody (as confirmed by SPR spectrometry) and the DFE ligand (as indicated by the loss of color and the lower DBC, Figure 3). The latter was anticipated given that native DsRed denatures at $\mathrm{pH}<4.0^{22,23}$. To avoid product and ligand denaturation, we tested magnesium chloride as an alternative elution agent because it has previously been used to elute mAbs from other affinity resins ${ }^{24}$. A magnesium chloride concentration of $1.25 \mathrm{M}$ was sufficient to elute $2 \mathrm{~F} 5$ from the DFE affinity resin with a recovery of $105 \pm 11 \%( \pm S D, n=3)$ and a purity of $97 \pm 3 \%( \pm S D, n=3)$. This performance was comparable to Protein $A$ resins ${ }^{25,26}$. The equilibrium dissociation constant $\left(K_{D}\right)$ of DFE-purified $2 F 5$ antibody and the synthetic ligand Fuzeon was $791 \mathrm{pM}$ whereas that of a Protein A-purified counterpart was $763 \mathrm{pM}^{5}$. Furthermore, no substantial color loss was observed in the resin over a total of 25 bind-and-elute cycles. The DBC of the DFE affinity resin at $10 \% 2 F 5$ breakthrough declined linearly over the course of 25 cycles to $\sim 15 \%$ of the initial value (Figure 3 ). 


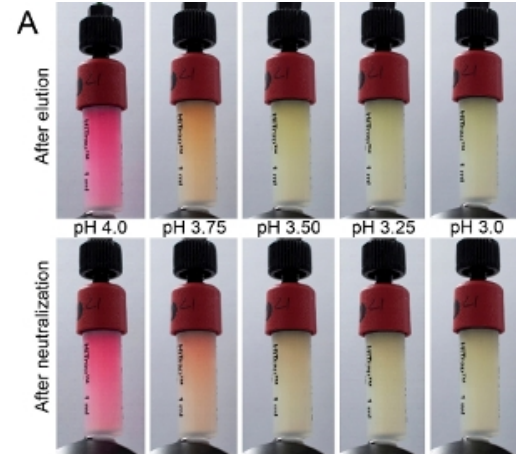

C

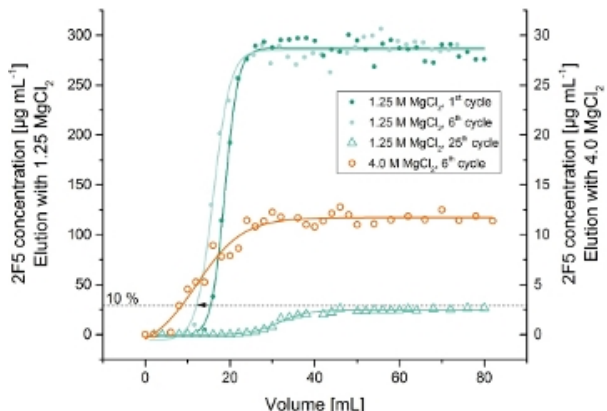

B

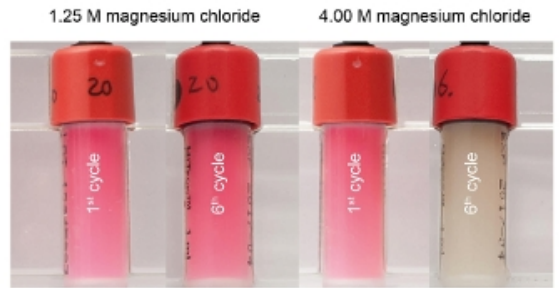

D

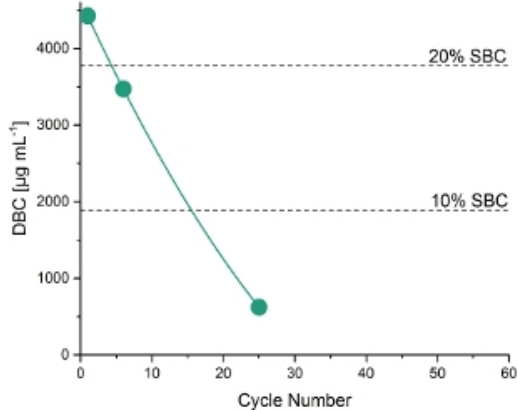

Figure 3: Testing the isolation of $2 \mathrm{~F} 5$ from clarified plant extracts using the DFE affinity resins. (A) DFE affinity resins after one elution cycle using buffers with different $\mathrm{pH}$ values in the range 4.0-3.0 and the same resins after a neutralization step at pH 6.0. (B) DFE affinity resins after one and six cycles of $2 \mathrm{~F} 5$ purification using $1.25 \mathrm{M}$ or $4.00 \mathrm{M}$ magnesium chloride as eluent. (C) Chromatograms of frontal loading experiments (break-through curves) to determine the cycle-dependent dynamic binding capacity of DFE resin using magnesium chloride as eluent. The break-through curves were measured for $4.0 \mathrm{M}$ and $1.25 \mathrm{M}$ magnesium chloride elution buffers and various cycle numbers. (D) Cycle-dependent dynamic binding capacity of DFE using 1.25 M magnesium chloride as eluent. Please click here to view a larger version of this figure.

\section{Discussion}

\section{Applications of the novel affinity resin}

We have shown that custom affinity chromatography resins for the capture of mAbs can be manufactured by immobilizing a ligand containing a mAb-specific epitope to NHS-activated cross-linked agarose. To design such a resin, it was necessary to know the epitope sequence and to use a linear epitope. The resulting resins are advantageous for the capture of $\mathrm{mAbs}$ because they could potentially replace expensive Protein $\mathrm{A}$ affinity chromatography steps. The interaction between 2F5 and DFE in our case study was mediated by epitope-paratope binding, so our ligand should be more selective than Protein A, which binds to the Fc region of most murine and human IgGs. Because individual ligands are needed for each mAb, our method may initially seem suitable mainly for antibodies that are produced on a very large scale. However, by combining our approach with rapid plant-based transient protein expression, new affinity ligands can be prepared in less than 2 weeks ${ }^{27}$ with minimal effort ${ }^{28}$. Hence, the method is also suitable for small-scale mAb purification.

\section{Production and potential improvements of the affinity ligand}

Plants offer a fast and safe production platform for affinity ligands ${ }^{5,29,30}$, such as the DFE fusion protein featured in our case study. Blanching the plant material greatly reduced the quantity of host cell proteins in a single step and was easily integrated into a standard clarification routine. However, the recovery of the ligand was low in the current setup, probably due to its moderate thermal stability and some non-specific binding to the filter layers, as reported for other products ${ }^{31,32,33}$. Engineering the carrier to increase its thermal stability may therefore help to improve the ligand yield in the future, as described for the malaria vaccine candidate CCT, the antitumor enzyme PpADI or a mesophilic $\beta$-glucosidase ${ }^{34,35,36}$. The same holds true for the depth filtration step, where protein engineering may help to reduce non-specific binding to the filter material ${ }^{37}$. The production costs for DFE and similar ligands could also be reduced by improving the overall efficiency of clarification using flocculants or filter additives $^{38,39}$

When DsRed is used as a carrier, it forms a tetrameric complex. This is advantageous because it increases the number of epitopes per ligand, but it may also render the ligand more susceptible to disassembly or denaturation during affinity chromatography. A monomeric carrier protein such as mCherry may therefore be preferable, because it is stable at low $\mathrm{pH}^{40}$, and the inclusion of tandem repeats of the epitope would increase the avidity of the ligand and thus increase resin capacity ${ }^{5,26,41}$. For simple carrier-epitope proteins (i.e., those with no disulfide bonds or post-translational modifications) microbial production systems may reduce the manufacturing costs and make the ligands more competitive with Protein A. For example, green fluorescent protein has been expressed in bacterial cells with a yield of $\sim 1 \mathrm{~g} \cdot \mathrm{kg}^{-1}$ biomass, which would significantly reduce ligand production costs ${ }^{42}$.

Regardless of the expression host, a purified affinity ligand was required during coupling to minimize the immobilization of host cell proteins or media components that can otherwise reduce resin selectivity and capacity. The inclusion of a poly-histidine tag for IMAC purification increased 
the purity to $\sim 90 \%$ in a single step, facilitating rapid and inexpensive ligand production ${ }^{5,43,44}$. However, the position of the fusion tag is important because it has the potential to sterically hinder epitope binding or to induce the cleavage of either the tag or the epitope from the carrier ${ }^{45,46}$.

\section{Immobilization of the affinity ligand on NHS-activated chromatography columns}

Immobilization was carried out manually or using a chromatography system. The small buffer volumes per column seemed to favor manual handling (e.g., due to the minimal waste volumes). However, if multiple/larger columns are needed, the chromatography system makes the coupling conditions easier to control (e.g., regulated flow rates) and is therefore more likely to achieve reproducible results in terms of DBC. Our data suggest that the coupling buffer and $\mathrm{pH}$ have an important effect on the coupling efficiency and overall column costs. Screening factors that influence the coupling reaction and adjusting them for each carrier protein (or even for each carrier-ligand fusion) could therefore improve coupling efficiency and resin performance, and we recommend this approach.

\section{Testing $2 \mathrm{~F} 5$ isolation using the DFE affinity resin}

Product yield and purity are important aspects of resin performance, and in the case of DFE we achieved a yield of $105 \pm 11 \%( \pm S D, n=3)$ and a purity of $97 \pm 3 \%( \pm S D, n=3)$, which is comparable with the performance of benchmark Protein A resins ${ }^{25,26}$. Another key performance indicator for resins in general (and particularly for those based on affinity ligands) is the DBC at $10 \%$ product breakthrough, because this parameter affects the amount of resin required for a specific process and thus the costs. For the DFE ligand, the initial DBC was $\sim 4 \mathrm{~g} \cdot \mathrm{L}^{-1}$ resin, which is $\sim 13 \%$ of the corresponding value for Protein $A$ under similar conditions (only 2 min contact time) ${ }^{25,47}$ but about 15 -fold higher compared to other custom affinity resins such as the anti-FSH-immunoaffinity ligand using the same residence time of $2 \mathrm{~min}^{48}$. The DBC of DFE declined to $15 \%$ of the starting value after 25 bind-and-elute cycles, whereas more than 50 cycles are required for the same loss of DBC in commercial Protein A resins ${ }^{49}$. However, it is important to note that our carrier has not yet been optimized to the same extent as Protein $\mathrm{A}$, which has been comprehensively investigated and improved over the last four decades ${ }^{8}$.

Thus far we have improved the resin stability and product recovery by switching from a low-pH elution buffer to a high concentration of magnesium chloride (Figure 3), as recommended in earlier studies ${ }^{13}$. The characteristic red color of the affinity ligand did not fade substantially during the 25 bind-and-elute cycles, so we speculate that endogenous plant proteases in the clarified plant extracts ${ }^{31}$ may have truncated and thus inactivated the epitope of the ligand. Therefore, designing protease-resistant linkers to connect the carrier and epitope may help to maintain the initial DBC over an extended number of cycles. Given the rapid and simple expression and purification of the DFE ligand, its straightforward coupling to commercial chromatography resins, and its excellent product yield and purity, we believe that our method offers a suitable alternative to Protein $\mathrm{A}$ for the purification of $\mathrm{mAbs}$ and antibody derivatives which do not bind to Protein $\mathrm{A}$, especially if improvements to the carrier and linker can improve the DBC and ligand stability. This assumption was supported by the small difference in the dissociation constant of DFEpurified and Protein A-purified 2F5 antibody ${ }^{5}$, indicating that our new affinity ligand allows the recovery of high-quality mAbs.

\section{Benefits and current limitations of the method}

Producing the affinity ligand as a genetic fusion with a carrier protein increases solubility in aqueous buffers and thus compatibility with typical ligand coupling conditions. In contrast, blank peptides derived from solid phase peptide synthesis may have limited solubility under these conditions due to their sequence ${ }^{50}$, which cannot be changed because it is dictated by the amino acid sequence of epitope recognized by the $\mathrm{mAb}$ to be purified. Others have therefore used an on-resin synthesis of peptide ligands ${ }^{51}$. The static binding capacity of the resulting resin was high $\left(\sim 80 \mathrm{~g} \cdot \mathrm{L}^{-1}\right)$, but the process of resin preparation is lengthy, a dynamic binding capacity was not reported and the obtained purity and recovery were lower than in our approach. An additional advantage of a fusion protein ligand in laboratory scale is that the ligand and variants thereof can be rapidly produced, purified and tested with minimal effort in an easy-to-use high-through expression system $^{52}$.

The two current limitations of the method presented here are the low dynamic binding capacity of $3 \mathrm{~g} \cdot \mathrm{L}^{-1}$ and its $90 \%$ reduction over the course of 25 bind-and-elute cycles ${ }^{5}$. These limitations can be addressed in the future by applying less stringent loading conditions and replacing the current DsRed carrier with an engineered, more stable variant respectively. For example, doubling the current contact time from 2 to 4 minutes has the potential to double the dynamic binding capacity as was shown for some Protein A resins ${ }^{26}$.

\section{Troubleshooting}

The following table highlights potential problems that can be encountered during this protocol and provides hints on how to solve them (Table 1). 


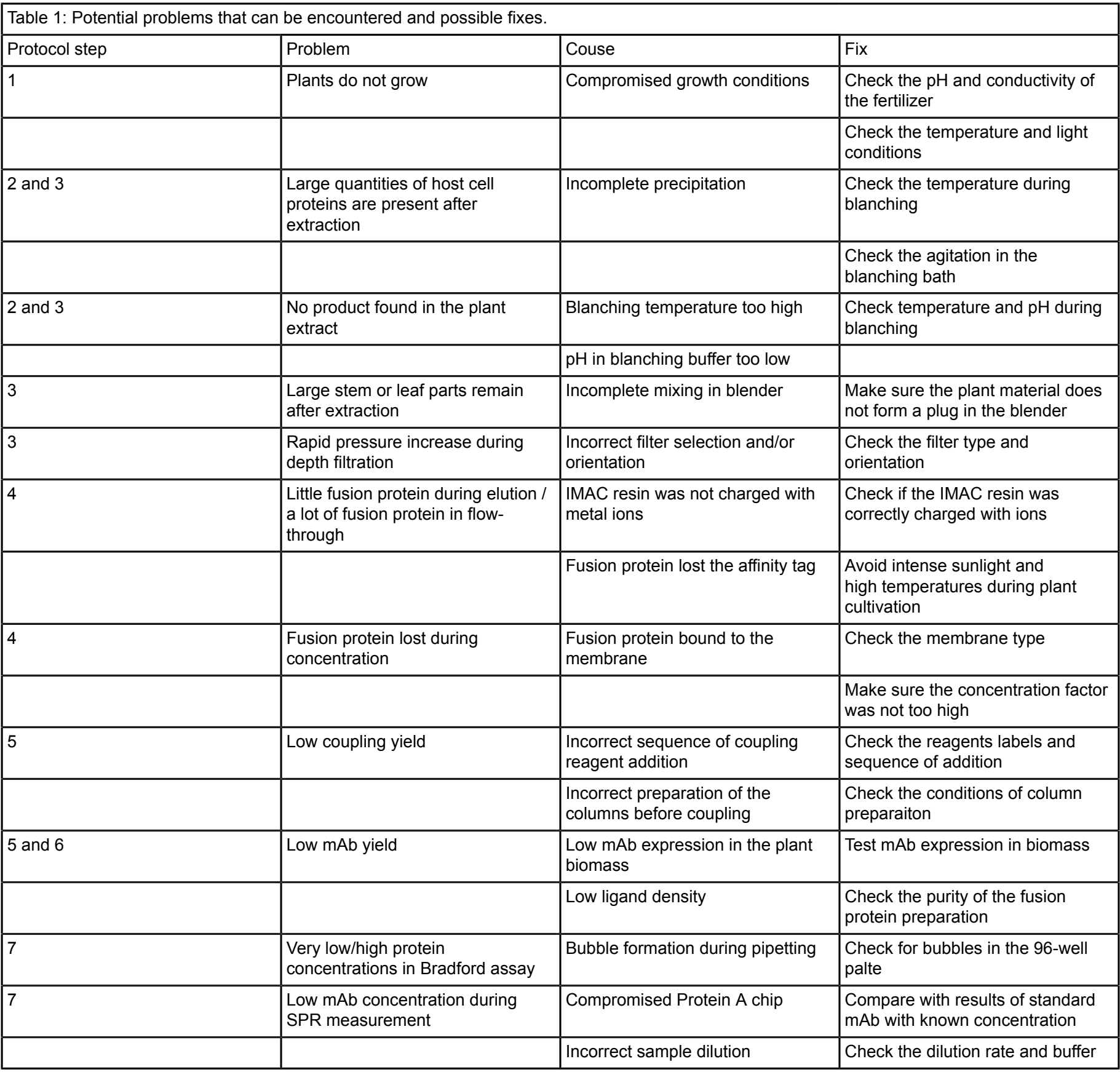

Table 1: Trouble-shooting.

\section{Disclosures}

The authors have no conflicts of interest to disclose.

\section{Acknowledgments}

We would like to acknowledge Ibrahim Al Amedi for cultivating the transgenic tobacco plants and Dr. Thomas Rademacher for providing the tobacco expression vector. The authors wish to thank Dr. Richard M. Twyman for editorial assistance and Markus Sack for fruitful discussions about the DFE affinity ligand structure. This work was funded in part by the Fraunhofer-Gesellschaft Internal Programs under Grant No. Attract 125-600164 and the state of North-Rhine-Westphalia under the Leistungszentrum grant no. 423 "Networked, adaptive production". This work was supported by the Deutsche Forschungsgemeinschaft (DFG) in the framework of the Research Training Group "Tumor-targeted Drug

Delivery" grant 331065168 . GE healthcare supported the open-access publication of this article. 


\section{References}

1. Kesik-Brodacka, M. Progress in biopharmaceutical development. Biotechnology and Applied Biochemistry. 65 (3), $306-322$ (2018).

2. Ecker, D.M., Jones, S.D., Levine, H.L. The therapeutic monoclonal antibody market. MAbs. 7 (1), 9-14 (2015).

3. Jayapal, K., Wlaschin, K. F., Hu, W. S., Yap, M. G. S. Recombinant Protein Therapeutics from CHO Cells - 20 Years and Counting. Chemical Engineering Progress. 103, 40-47 (2007).

4. Kunert, R., Reinhart, D. Advances in recombinant antibody manufacturing. Applied Microbiology and Biotechnology. 100 (8), $3451-3461$ (2016).

5. Rühl, C., Knödler, M., Opdensteinen, P., Buyel, J. F. A linear epitope coupled to DsRed provides an affinity ligand for the capture of monoclonal antibodies. Journal of Chromatography A. 1571, 55-64 (2018).

6. Edgue, G., Twyman, R. M., Beiss, V., Fischer, R., Sack, M. Antibodies from plants for bionanomaterials. Nanomedicine and Nanobiotechnology. 9 (6), e1462 (2017).

7. Buyel, J.F., Fischer, R. Very-large-scale production of antibodies in plants: The biologization of manufacturing. Biotechnology Advances. 35 (4), 458-465 (2017).

8. Bolton, G.R., Mehta, K.K. The role of more than 40 years of improvement in protein A chromatography in the growth of the therapeutic antibody industry. Biotechnology Progress. 32 (5), 1193-1202 (2016).

9. Kelley, B. Industrialization of mAb production technology: the bioprocessing industry at a crossroads. MAbs. 1 (5), $443-452$ (2009).

10. Brochier, V., Ravault, V. High throughput development of a non protein A monoclonal antibody purification process using mini-columns and bio-layer interferometry. Engineering in Life Sciences. 16 (2), 152-159 (2016).

11. Arakawa, T., Futatsumori-Sugai, M., Tsumoto, K., Kita, Y., Sato, H., Ejima, D. MEP HyperCel chromatography II: binding, washing and elution. Protein Expression and Purification. 71 (2), 168-173 (2010).

12. Barroso, T.B., R. J. Aguiar-Ricardo, A. Roque, A. C. Structural evaluation of an alternative Protein A biomimetic ligand for antibody purification. Journal of Computer-aided Molecular Design. 28 (1), 25-34 (2014).

13. Mazzer, A.R., Perraud, X., Halley, J., O'Hara, J., Bracewell, D.G. Protein A chromatography increases monoclonal antibody aggregation rate during subsequent low pH virus inactivation hold. Journal of Chromatography A. 1415, 83-90 (2015).

14. Sack, M. et al. Functional analysis of the broadly neutralizing human anti-HIV-1 antibody $2 \mathrm{~F} 5$ produced in transgenic BY-2 suspension cultures. FASEB Journal. 21 (8), 1655-1664 (2007).

15. Buyel, J.F., Fischer, R. Characterization of Complex Systems Using the Design of Experiments Approach: Transient Protein Expression in Tobacco as a Case Study. Journal of Visualized Experiments. (83), 51216 (2014).

16. Trasatti, J.P., Woo, J., Ladiwala, A., Cramer, S., Karande, P. Rational design of peptide affinity ligands for the purification of therapeutic enzymes. Biotechnology Progress. 34 (4), 987-998 (2018).

17. Buyel, J.F., Gruchow, H. M. Boes, A., Fischer, R. Rational design of a host cell protein heat precipitation step simplifies the subsequent purification of recombinant proteins from tobacco. Biochemical Engineering Journal. 88, 162-170 (2014).

18. Simonian, M.H., Smith, J.A. Spectrophotometric and colorimetric determination of protein concentration. Current Protocols in Molecular Biology. 76 (Chapter 10), 10.11.11-10.11A.19. (2006).

19. Buyel, F.J., Kaever, T., Buyel, J., Fischer, R. Predictive models for the accumulation of a fluorescent marker protein in tobacco leaves according to the promoter/5'UTR combination. Biotchnology and Bioengeneering. 110 (2), 471-483 (2013).

20. Piliarik, M., Vaisocherova, H., Homola, J. Surface plasmon resonance biosensing. Methods in Molecular Biology. 503, 65-88 (2009).

21. Buyel, J.F., Fischer, R. Scale-down models to optimize a filter train for the downstream purification of recombinant pharmaceutical proteins produced in tobacco leaves. Biotechnology Journal. 9 (3), 415-425 (2014).

22. Baird, G.S., Zacharias, D.A., Tsien, R.Y. Biochemistry, mutagenesis, and oligomerization of DsRed, a red fluorescent protein from coral. Proceedings of the National Academy of Sciences, USA. 97 (22), 11984-11989 (2000).

23. Vrzheshch, P.V., Akovbian, N.A., Varfolomeyev, S.D., Verkhusha, V.V. Denaturation and partial renaturation of a tightly tetramerized DsRed protein under mildly acidic conditions. FEBS Letters. 487 (2), 203-208 (2000).

24. Firer, M.A. Efficient elution of functional proteins in affinity chromatography. Journal of Biochemical and Biophysical Methods. 49 (1-3), 433-442 (2001).

25. Pabst, T.M. et al. Engineering of novel Staphylococcal Protein A ligands to enable milder elution pH and high dynamic binding capacity Journal of Chromatography A. 1362, 180-185 (2014).

26. Müller, E., Vajda, J. Routes to improve binding capacities of affinity resins demonstrated for Protein A chromatography. Journal of Chromatography B. 1021, 159-168 (2016).

27. Shamloul, M., Trusa, Jason, Mett, Vadim, Yusibov, Vidadi. Optimization and Utilization of Agrobacterium-mediated Transient Protein Production in Nicotiana. Journal of Visualized Experiments. (86), 51204 (2014).

28. Rademacher, T. et al. Plant cell packs: a scalable platform for recombinant protein production and metabolic engineering. Plant Biotechnology Journal. (2018).

29. Saxena, L., lyer, B.K., Ananthanarayan, L. Purification of a bifunctional amylase/protease inhibitor from ragi (Eleusine coracana) by chromatography and its use as an affinity ligand. Journal of Chromatography. B. 878 (19), 1549-1554 (2010).

30. Kurppa, K., Reuter, L. J., Ritala, A., Linder, M. B., Joensuu, J. J. In-solution antibody harvesting with a plant-produced hydrophobin-Protein A fusion. Plant Biotechnology Journal. 16 (2), 404-414 (2018).

31. Menzel, S. et al. Optimized Blanching Reduces the Host Cell Protein Content and Substantially Enhances the Recovery and Stability of Two Plant-Derived Malaria Vaccine Candidates. Frontiers in Plant Science. 7 (159), 1-7 (2016).

32. Yigzaw, Y., Piper, R., Tran, M., Shukla, A.A. Exploitation of the adsorptive properties of depth filters for host cell protein removal during monoclonal antibody purification. Biotechnology Progress. 22 (1), 288-296 (2006).

33. Menzel, S. et al. Downstream processing of a plant-derived malaria transmission-blocking vaccine candidate. Protein Expression and Purification. 152, 122-130 (2018).

34. Vöpel, N., Boes, A., Edgü, G.. Beiss, V. Malaria vaccine candidate antigen targeting the pre-erythrocytic stage of Plasmodium falciparum produced at high level in plants. Biotechnology Journal. 9 (11), 1435-1445 (2014) 
35. Lee, C.W., Wang, H. J., Hwang, J. K., Tseng, C. P. Protein thermal stability enhancement by designing salt bridges: a combined computational and experimental study. PLOS ONE. 9 (11), e112751 (2014).

36. Zhu, L., Cheng, F., Piatkowski, V., Schwaneberg, U. Protein engineering of the antitumor enzyme PpADI for improved thermal resistance. Chembiochem. 15 (2), 276-283 (2014).

37. Khanal, O. et al. Contributions of depth filter components to protein adsorption in bioprocessing. Biotechnology and Bioengineering. 115 (8), 1938-1948 (2018).

38. Buyel, J.F., Fischer, R. Downstream processing of biopharmaceutical proteins produced in plants: the pros and cons of flocculants. Bioengineered. 5 (2), 138-142 (2014).

39. Buyel, J.F. Procedure to Evaluate the Efficiency of Flocculants for the Removal of Dispersed Particles from Plant Extracts. Journal of Visualized Experiments. (110), e53940 (2016).

40. Fink, D. et al. Ubiquitous expression of the monomeric red fluorescent protein mCherry in transgenic mice. Genesis. 48 (12), $723-729$ (2010).

41. Gagnon, P. Technology trends in antibody purification. Journal of Chromatography A. 1221, 57-70 (2012).

42. Figueira, M., Laramée, L., Murrell, J. C., Groleau, D., Míguez, C. Production of green fluorescent protein by the methylotrophic bacterium Methylobacterium extorquens. FEMS Microbiology Letters. 193 (2), 195-200 (2001).

43. Bornhorst, J.A., Falke, J. J. Purification of proteins using polyhistidine affinity tags. Methods in enzymology. 326, 245-254 (2000).

44. Sainsbury, F., Jutras, P. V., Vorster, J., Goulet, M., Michaud, D. A Chimeric Affinity Tag for Efficient Expression and Chromatographic Purification of Heterologous Proteins from Plants. Frontiers in Plant Science. 7, 141-141 (2016).

45. Krupka, M. et al. The Position of His-Tag in Recombinant OspC and Application of Various Adjuvants Affects the Intensity and Quality of Specific Antibody Response after Immunization of Experimental Mice. PLoS ONE. 11 (2), e0148497 (2016).

46. Goel, A. et al. Relative position of the hexahistidine tag effects binding properties of a tumor-associated single-chain Fv construct. Biochimica et Biophysica Acta. 1523 (1), 13-20 (2000).

47. Tustian, A.D. et al. Development of a novel affinity chromatography resin for platform purification of bispecific antibodies with modified protein a binding avidity. Biotechnology Progress. (2018).

48. Zandian, M., Jungbauer, A. An immunoaffinity column with a monoclonal antibody as ligand for human follicle stimulating hormone. Journal of Separation Science. 32 (10), 1585-1591 (2009).

49. Kelley, B. Very large scale monoclonal antibody purification: the case for conventional unit operations. Biotechnology Progress. 23 (5), 995-1008 (2007).

50. Petrou, C., Sarigiannis, Y. In: Peptide Applications in Biomedicine, Biotechnology and Bioengineering. Koutsopoulos, S., ed., Ch. 1, Woodhead Publishing, Cambridge, 1-21 (2018).

51. Menegatti, S. et al. Design of protease-resistant peptide ligands for the purification of antibodies from human plasma. Journal of Chromatography A. 1445, 93-104 (2016).

52. Rademacher, T. et al. Plant cell packs: a scalable platform for recombinant protein production and metabolic engineering. Plant Biotechnology Journal. 1-7 (2019). 